\title{
Choice of Unattainable Group Goals and Effects on Performance ${ }^{1}$
}

\author{
John Forward ${ }^{2}$ and Alvin ZANDER \\ Research Center for Group Dynamics, University of Michigan
}

\begin{abstract}
This study is an experimental investigation of several factors which may account for an earlier survey finding that United Fund organizations which persistently fail to attain campaign goals do so mainly because they set goals which are virtually unattainable in the light of prior performances. Four-man teams of high school boys worked on an interdependent group skills task in competition with teams from nearby schools. Three conditions were studied: (a) apparent success of own team (b) prior success of school to which team belonged and (c) strength of external pressures to raise group aspirations to high levels. Results show that all three factors have independent and additive effects on increasing the positive discrepancy between past performance and future goals. It is also shown that there is a negative relationship between size of goal discrepancy and subsequent performance for failing teams but no relationship is found for successful teams. The implications of these results for goal setting in United Funds and for group decision making are discussed.
\end{abstract}

Experimental studies of group aspirations have consistently shown that group members in whom the tendency to approach group success is stronger than the tendency to avoid group failure prefer aspirations of more intermediate difficulty for their group than members in whom the group avoidant tendency is stronger than the approach tendency (Zander, 1968; Forward, 1969; Zander \& Forward, 1968).

The generality of these and other findings on group achievement motivation has been tested recently in two studies of United Fund organizations which annually set campaign goals and receive unambiguous performance feedback with respect to these goals (Zander $\&$ Newcomb, 1957; Zander, Forward, \& Albert, 1969). The results of both studies demonstrate that strong phenotypic similarities exist between goal-setting within small laboratory groups and United Fund

${ }^{1}$ This researeh was supported by the Air Force Office of Scientific Research, Contract No. AF 49(638)-1630. Requests for reprints should be sent to Alvin Zander, Research Center for Group Dynamics, P. O. Box 1248, Ann Arbor, Michigan 48106.

${ }^{2}$ Now at the University of Colorado. 
organizations. One striking similarity is that failing towns, like failing laboratory groups, set goals which are of more extreme difficulty than towns which are successful. For example, in a matched sample of 32 towns with four consecutive campaign successes and 32 towns with four failures, no significant difference was found for percentage performance improvement over a period of four years (av. $9 \%$ and $6 \%$, respectively). However, the failing towns set goals which averaged $18 \%$ above the past year's income compared with $6 \%$ for successful towns (Zander, Forward \& Albert, 1969).

There are at least three alternative but not mutually exclusive hypotheses concerning conditions which give rise to the choice of unattainable campaign goals. The first is a direct generalization from small group studies which have shown that repeated group failure arouses strong dispositions among members to avoid the negative consequences of failure (Zander, 1968; Zander \& Medow, 1965). If we assume that similar motivational consequences occur for UF board members of repeatedly failing towns, the excessively high goal-setting may be seen as a means of aroiding the negative consequences of failure by making the goal irrelevant as a criterion for group achievement. A supportive finding is that members of failing towns report much less use of official goal attainment as their personal criterion for a "successful" campaign than do members in successful towns (Zander, Forward \& Albert, 1969).

A second hypothesis takes account of the fact that in a United Fund setting, the goal represents not only a potential criterion for measuring achievement but is also an indicator of stated dollar needs for welfare within a community. Goal setting therefore, may simply be a decision on the part of board members to match the dollar amount of a campaign goal to some dollar estimate of welfare needs in a community. Although no differences have been found for percentage performance improvement, failing towns are significantly poorer performers than successful towns in terms of per capita income and also for income per unit of estimated consumer wealth available within a town (Zander, Forward \& Albert, 1969). This, together with the common observation that continual failure tends to highlight unmet needs, makes it reasonable to assume that the relative estimates of dollar needs for welfare are higher in habitually failing towns than in successful towns. A simple decision to match dollar amount of goal to the available estimate of dollar need would be sufficient to explain the results under consideration here.

It is important to note that whereas the first hypothesis assumes that UF boards pay close attention to expectancy variables in setting goals, an important assumption underlying the second hypothesis is 
that expectancy or probability estimates are irrelevant to the goal setting procedure. Goal setting is assumed to be a cognitive matching process without any of the motivational assumptions underlying the first hypothesis.

A third hypothesis accounts for an aspect of a United Fund environment which is rarely so strongly present in laboratory groups, that is, the strength of pressures from sources external to the executive board to raise the level of a campaign goal. Even in laboratory groups, pressures from outside observers to change group aspirations have had marked effects on the aspirations which members of performing groups select for themselves (Zander, Medow \& Efron, 1965). In UF settings, it is reasonable to assume that community pressures on the budget are uniformly in an upward direction and, as already stated, these pressures may be stronger upon boards of failing towns than upon successful boards. An altenrative explanation is to assume that the strength of external pressures is the same for successful and failing Funds but that members of failing boards are more vulnerable to these pressures. Successful towns, by virtue of their success in raising money and meeting local needs, may simply have greater control over budgeting operations and so may better resist pressures to raise the campaign goal to unreasonable levels.

While each of the three hypotheses has some support in survey data, the nature of survey methodology makes it difficult to assess the relative independence of each factor and possible joint effects among them. Also, correlational data make it difficult to assess directional effects within the apparently circular chain of events from poor campaign performance to increased need to increased pressures to choice of unattainable goals and back to poor performance.

The present study attempts to create experimental conditions in which the three hypotheses may be systematically tested. In particular, we are interested in the relative effects of three factors upon the choice of a group aspiration; (a) the success or failure of a member's own group, (b) the prior success or failure of a larger organizational unit to which a group belongs and (c) the strength of external pressures towards unreasonably high goals brought to bear on a group which is responsible to the larger organization. The first factor is assumed to affect the relative strength of group success and group failure tendencies among members and so provides a test of the first hypothesis. The second factor is assumed to lead to differences among teams in perceived need for school points and so provides a condition for testing the second hypothesis and the third factor, strength of external pressures, is designed to test the third hypothesis. 
In addition to these hypotheses concerning group aspirations, the use of a standard group task and standardized performance feedback makes possible a more controlled investigation of the relationship between group aspirations and group performance. Evidence from an analysis of official UF records indicates a curvilinear relationship between size of positive goal-discrepancy and future performance for a sample of 149 UF organizations (Zander \& Newcomb, 1967). At some point, increasing the level of a future campaign goal above a prior performance level begins to have a negative rather than a positive effect on future campaign performance. This finding is tested experimentally in the present study.

\section{METHOD}

\section{Subjects and Setting}

Sixty-four junior boys from a large suburban high school were randomly assigned to four-man groups. The study was conducted in a vacant room in the school. The use of a high-school setting enabled us to simulate several important features of UF board membership and decision-making. Members of experimental groups were able to identify with a larger community to which their group belonged, i.e., the school. Moreover, since each group worked to achieve the highest number of points for an overall school score, members believed that their group was both representative of and working on behalf of a wider community.

\section{Experimental Group Task}

Requirements for an appropriate group task are that it must vary in level of difficulty so that group aspirations may vary, that clear group performance feedback be obtained for each trial, that it provide for task interdependence among members, that it minimize individual differences in skill among members and yet be sufficiently challenging to provide arousal cues for group achievement tendencies.

A group task which meets these criteria is one developed by Forward (1969). To provide for the arousal of group achievement motivation, the task was described to subjects as a "Team Coding Capacity Task" which was designed to test their coding skills and their ability to work efficiently as a team. It was explained further that the group would be working for a team score over a series of trials, that the team score would be added to a total score for all teams in their school and that the school score would then be compared with the total scores of other nearby high schools. Following this brief introduction, the group 
task was explained and two practice trials were run to ensure familiarity with the procedures.

For each trial, each of the four group members received a modified IBM card which had nine fields of numbers with four columns of numbers per field (numbers 1 through 5 within each column). To complete one field, each number circled a number in field 1, column 1 and passed his card to the person sitting to his right who then circled a number in the next column and passed it on. This procedure of circling one column and passing the card on continued until time ran out for each trial. Circling a number in the fourth and final column of each field required extra care since at the bottom of each field was a printed "Field Total" and the four circled numbers within the field were required to add to this total. Field totals were the same for all fields on all cards within a trial, but were different across trials. To standardize the performance conditions across teams, low partitions separated team members (they could see each other but not their individual work) and communication among members while trials were in progress was not permitted. Post questionnaire data from this and previous studies indicate that most participants become highly involved in the group effort and consider the group task to be challenging.

\section{Task Diffculty and Aspirations for the Group}

Different levels of task difficulty were created by setting the same standard time limit for each trial and asking members to state aspirations for their group in terms of the number of fields they thought their team should try to complete within the time limit. A large chart was displayed for all teams showing the proportion of teams which had been able to complete each level of difficulty (i.e., fields 1 to 9) within the standard time limit. The proportion of successful teams was shown to be inversely related to increasing levels of difficulty.

Before each trial, each member selected privately his aspiration for the group in terms of the number of fields he would personally like to see the team try to complete within the standard time limit. After collecting these private aspirations, the experimenter selected the level of aspiration with the greatest number of choices and announced it as the official team goal. This goal level was posted on the difficulty chart. Second preferences were used to break ties which occurred for first preferences.

\section{Team Points and School Score}

After each trial, teams received credit for the actual number of fields completed within the standard time limit. The number of points 
to be gained for group achievement at each level of difficulty on the task was represented on the chart in front of them, (1 point for each completed field). This practice of receiving credit for what is actually obtained whether or not the official goal is reached resembles the performance conditions in United Fund campaigns.

On a separate chart, a cumulative total of team points was kept for each team over trials. Also shown were average total scores for other teams in the same high school (own school score) and average scores for all other schools. In this way, each team had a clear indication of how well their school was doing and how well their own team was progressing over trials. Although subjects believed that one time limit was standard for all teams, feedback conditions were systematically varied as described below.

\section{Experimental Conditions and Predictions}

Three experimental conditions, each designed to test one of the three hypotheses, were incorporated in a 3 factorial design. Sixteen groups were randomly assigned to conditions.

1. Team success or failure. For all trials on the task, the Experimenter covertly manipulated the standard time limit so that the amount completed and therefore the number of team points obtained conformed to prearranged schedules. Teams assigned to the Team Failure condition $(n=8)$ were led to believe that their team was doing poorly under the supposed standard time limit by obtaining scores of only 2 and 3 for the practice trials and $2,3,4,5$, and 5 for the five test trials. The total team score for failing teams was 19. This compared with the overall average for teams in other schools of 24 . For successful teams $(n=8)$, the time limit was adjusted to give feedback of 4 and 5 for the practice trials, and 4, 5, 6, 7 and 7 for the five test trials, giving them a total team score of 29 .

Based on the results of previous studies (Zander, 1968), we assume that repeated group failure will give rise to strong tendencies among members of failing teams to avoid the negative consequences of failure. One avoidance strategy is to select goals for the group which are not challenging and which cannot be used as clear criteria for group achievement. On the assumption that the most challenging goal is one for which the subjective probability for group success is .50, we expect that members of failing groups will select group goals which are more extreme in terms of subjective expectancies for group success than members of successful teams.

In other words, the amount of discrepancy between prior performance levels and future goals will be greater for failing than succeeding 
teams (Prediction 1). A significant main effect for goal discrepancies under this prediction will be assumed to be support for the first hypothesis concerning the antecedents of choice of unattainable group goals.

2. School need for points. To approximate the difference in perceived need for welfare money between successful and failing UF towns, teams coming into the experimental situation faced differences with respect to the competitive position of their school in relation to other schools. For groups in a Low School Need condition $(n=8)$, the alleged average score for other teams within their school was set at 28 points, which was 4 points above the average of other schools. For groups in the High School Need condition $(n=8)$, the school average was represented as being only 18 points, 6 points below other schools. This information was given to teams after the practice trials and before the start of the test series. All teams were told that about half the teams from their school had already performed on the group task.

If we assume that members of teams in less successful schools face a greater need to gain a large number of team points for their school than members of teams in successful schools, this condition is appropriate for testing the second hypothesis. The hypothesis is that excessively high group goals are set simply by matching the goal to some estimate of need (either money or team points). The prediction associated with this hypothesis is that the size of the discrepancy between prior performance and future group goals will be greater for teams in the High School Need than the Low School Need condition (Prediction 2). A significant effect for this prediction will be assumed to support the second hypothesis.

3. External group pressures. To simulate pressures from agencies and other groups external to UF executive boards toward raising the level of campaign goals, each team received a recommendation from a School Standards Committee before the start of the test trials. It was explained that the Committee consisted of six senior boys selected for their overall leadership ability and that their task was to keep track of how their school was doing. The recommendation stated that their schools was (going ahead/falling behind) other schools and that the Committee wanted every team to try to get as many points as possible so that the school could finish in first place. For groups in the Strong Pressures group condition $(n=8)$, the statement went on the say that it was recommended strongly that teams try for goals of 7 or 8 fields for each trial since if they achieved these goals all teams would end up with a total of 40 points and the school would finish out in front. The remaining teams in the Weak Pressures condition were told that the Committee did not have specific recommendations at the 
present time except that all teams should try their hardest to get points for the school.

The group pressures condition was designed to test the third hypothesis that excessively high goals in UF campaigns are the result of external pressures to raise goal levels. The prediction is that members of teams in the Strong Pressures condition will obtain larger discrepancies between prior performance levels and future goals than will members of teams in the Weak Pressures condition (Prediction 3). A significant main effect for this condition will be assumed to support the third hypothesis.

\section{RESULTS}

\section{Group Aspirations}

The major dependent variable is the aspiration a member selects for his group prior to each trial. To assess the amount that each aspiration exceeded the immediately prior group performance, a goaldiscrepancy score was used. This score is the signed difference between the number of fields completed on trial $n$ and the number of fields stated as a group aspiration for trial $n+1$. Mean goal-discrepancy scores over five trials are shown in Table 1 . From Table 1 it may be observed that members of successful teams with low need for school points and facing weak pressures select group aspirations over trials very much in line with the mean amount of performance improvement across trials (both 0.6 fields per trial). At the other extreme, members of failing teams with high need for school points and strong external pressures upon them, select group goals which exceed by a factor of 3 the mean performance improvement of teams. ${ }^{3}$

As shown by the ordering of means and the results of an analysis of variance (Table 2), each of the experimental factors has an independent and additive effect on the tendency to raise group goals above levels that are reasonably attainable in the light of past performance. All three predicted main effects are significant and there are no significant interactions. Together, the three main effects account for $17 \%$ of the total variance in goal-discrepancy scores.

A separate analysis of goal-discrepancy scores based on second preferences for group goals showed results similar to those for first preferences presented above. Significant main effects were obtained for Team Performance $(F=4.21, d f=1,56, p<.05)$ and School Need $(F=6.49$, df $=1,56, p<.05)$ but no effect was found for External

\footnotetext{
${ }^{3}$ It may be noted that failing UF towns also set goals which on the average exceeded percent performance increases by a factor of 3 .
} 
TABLE 1

Size of Goal Discrepancy Per Trial; Mean Trials $1-5^{*}$

\begin{tabular}{lcccc} 
& \multicolumn{3}{c}{ School Need for points } \\
\cline { 2 - 5 } $\begin{array}{c}\text { Team } \\
\text { perform- } \\
\text { ance }\end{array}$ & Strong pressures & Weak pressures & Strong pressures & Weak pressures \\
\cline { 2 - 5 } Failure & 1.90 & 1.53 & 1.35 & 0.98 \\
Success & 1.23 & 1.03 & 1.20 & 0.60 \\
\hline
\end{tabular}

* For comparison, the average performance increment per trial for all conditions is 0.6 fields.

Pressures $(F=1.54, N S)$. No significant interactions were obtained. By countering the expected regression effects for second choices, Team Performance and School Need are shown to be fairly stable factors influencing group aspiration choice whereas the External Pressures factor appears to be less stable in its effect.

Trial by trial analyses revealed that effects are consistent across trials but that there were systematic changes in the relative strengths of effects over time. External Pressures had their strongest effect on the first two trials, Team Performance differences were greater for middle trials, and the strongest School Need effect occurred on the last trial. Only one significant interaction was found in all five analyses and it was essentially uninterpretable. The pattern of the relative strengths of main effects observed over trials appears to be an artifact due to the nature of the experimental inductions. The External Pressures induction was given at the start of trials and only once, Team Performance feedback occurred after each trial, and the School Need for points would be likely to become more salient toward the end of

TABLE 2

Analysis of Vartance for Mean Size Discrepancy Scores Trials 1-5

\begin{tabular}{lrrr}
\hline \multicolumn{1}{c}{ Source } & $d f$ & $M S$ & $F$ \\
\hline Team performance (A) & 1 & 2.89 & $5.16^{*}$ \\
School Need (B) & 1 & 2.40 & $4.29^{*}$ \\
External pressures (C) & 1 & 2.40 & $4.29^{*}$ \\
$\mathrm{~A} \times \mathrm{B}$ & 1 & 0.01 & $<1$ \\
$\mathrm{~A} \times \mathrm{C}$ & 1 & 0.43 & $<1$ \\
$\mathrm{~B} \times \mathrm{C}$ & 1 & 0.17 & $<1$ \\
$\mathrm{~A} \times \mathrm{B} \times \mathrm{C}$ & 1 & 0.14 & $<1$ \\
Error & 56 & 0.56 & \\
\hline
\end{tabular}

${ }^{*} p<.05$. 
the trials when teams had developed a clearer estimate of their final team score.

The responses to several post-experimental questions add additional support to the hypotheses of the study. All questions were answered on a 7 point scale. As expected, members of Success groups rated their team higher than members of Failing teams in their evaluation of how well their team had performed (Mns. 5.18 and $4.00, F=12.48, p<.01$ ). However, members of Success teams more than members of Failing teams also rated their own individual performance better (Mns. 5.12 and $4.46, F=3.96, p<.06$ ), and accepted more responsibility for either helping or hurting the school score (Mns. 5.28 and 4.31, $F=8.91$, $p<.01)$. These are typical findings for team members in whom strong group achievement tendencies have been aroused (cf. Zander \& Forward, 1968).

A result which replicates a finding for United Fund organizations is that Successful team members attached greater importance to the necessity of setting official team goals than members of Failing teams (Mns. 5.16 and $4.02, F=5.03, p<.05$ ). One pair of questions designed to test the idea that Failing groups pay less attention to expectancy variables than Successful groups produced results opposite to what was expected. In response to the question, "How important it is to attempt the highest possible number of points on each trial," Success team members gave a higher rating than Failing team members (Mns. 5.97 and $4.97, F=8.30, p<.01$ ). For the question, "How important is it to try for goals the team can actually achieve on each trial," Success team members gave lower ratings than Failing team members (Mns. 4.44 and 5.50, $F=5.76, p<.05$ ). No ready explanation exists for these findings, other than question ambiguity, since the analyses of goal-discrepancy scores clearly indicate that Failing teams did not actually choose goals which they could achieve but instead tried for an unreasonably high number of team points.

Apart from an expected difference between High Need and Low Need teams with respect to their perceptions of how well their school was doing (Mns. 2.88 and 5.56, $F=80.89, p<.01$ ), the only significant difference for the School Need factor is that High Need team members rated it more important that their team do better than other teams than Low Need members (Mns. 5.53 and $4.63, F=6.72, p<.05$ ). This response further illustrates the independence between perception of need and intrinsic group achievement motivation, since typically successful teams respond more competitively than failing teams. No effects at all were obtained on the post-questionnaire for differences between Strong and Weak Pressures conditions. 


\section{Tieam Performance}

Since teams did not receive information about their school's score or recommendations from the "Standards Committee" until after the practice trials, it is possible to check on initial base line performance differences among groups. An analysis of variance for mean seconds per field completed on the two practice trials revealed no significant differences; $F$ ratios for School Need and External Pressures main effects were less than 1.00. Since team performance feedback was given following the first practice trial, it is the only uncontaminated trial. For practice trial 1, mean seconds per field was exactly the same for teams assigned to Success and Failure conditions (19.7 secs). These results clearly show that teams did not differ in performance prior to the experimental inductions.

An analysis of variance for mean seconds per field over the five test trials revealed two main effects. Figure 1 shows that Successful teams performed better than Failing teams $(F=3.47, d f=1,8, p<.10)$.

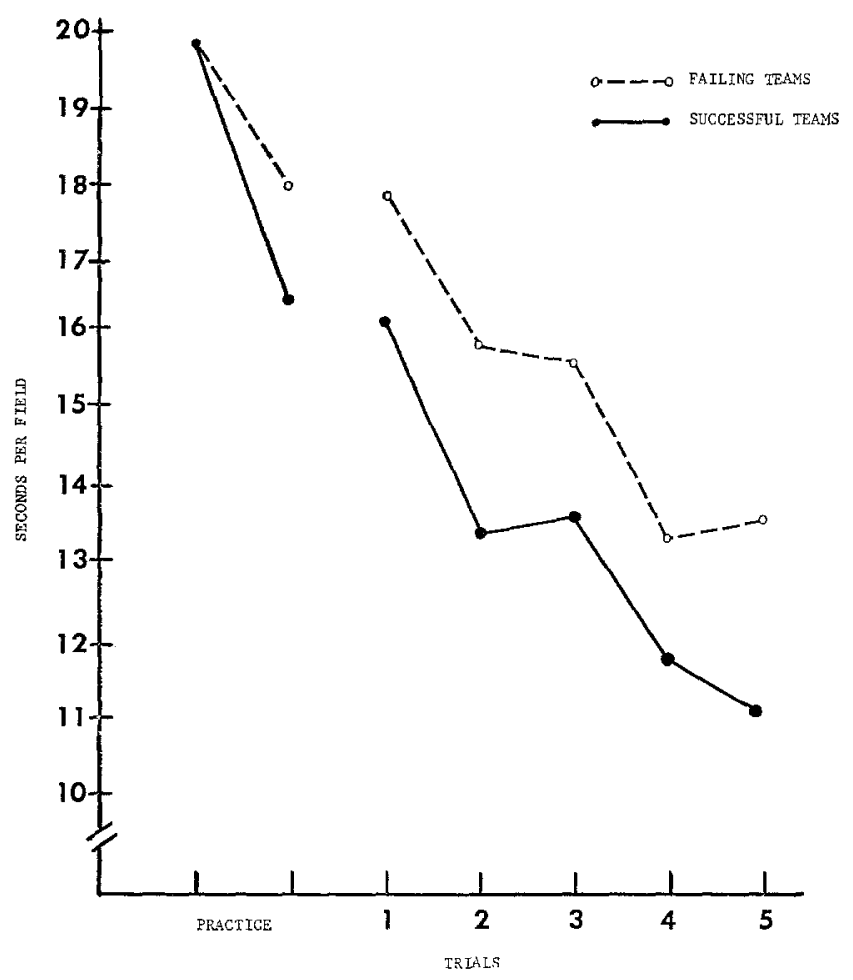

Fig. 1. Mean seconds per field over trials for the Team Performance feedback condition. 
Figure 2 shows that groups in the Low Need condition performed better than groups in the High Need condition $(F=5.19$, df $=1,8$, $p<.06$ ). All other effects for performance had $F$ ratios less than 1.00 . Although these main effects are fairly weak, inspection of performance trends over trials reveals that the mean differences become somewhat larger toward the last trials, particularly for the School Need conditions. For example, whereas no reliable differences were found for the first test trial, trial 5 showed an $F$ ratio of $8.43(p<.025)$ for School Need. From these results, it is apparent that differences in team performance feedback and school need for points have independent and additive effects on group performance.

In United Fund campaigns, a curvilinear (inverted U) relationship has been found between size of positive goal discrepancy and subsequent performance improvement (Zander \& Newcomb, 1967). For all teams in the present study, a slightly negative relationship is obtained for size of goal discrepancy and group performance (rho $=-0.32$,

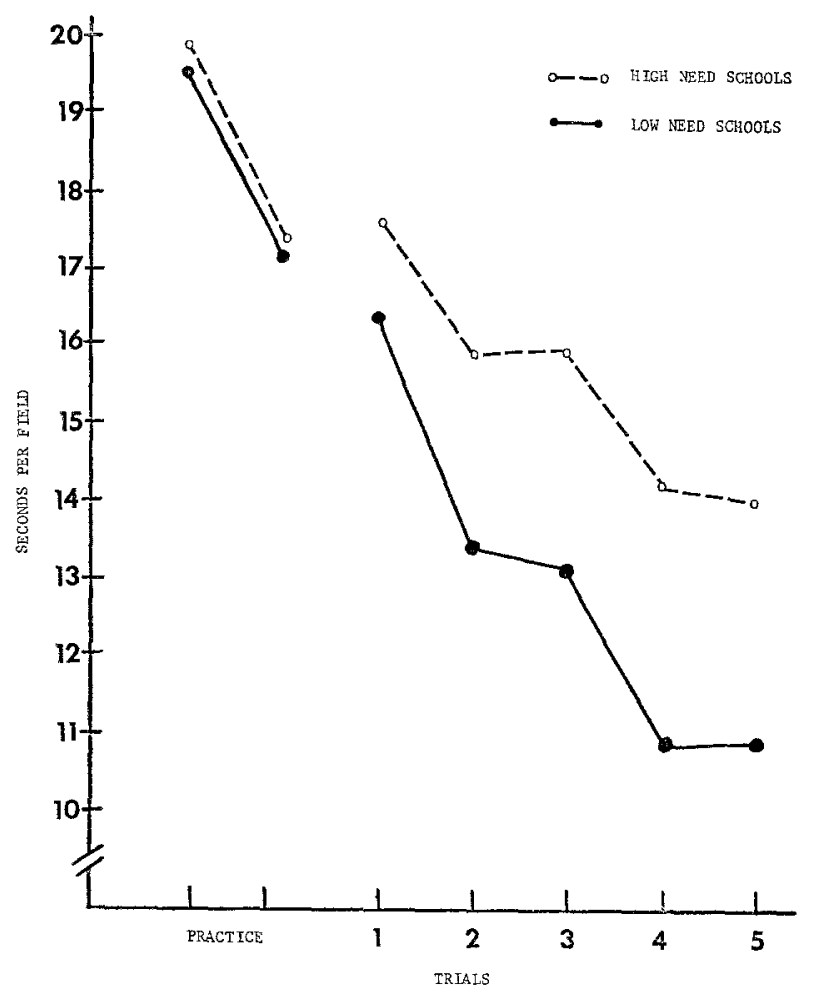

Frg. 2. Mean seconds per field over trials for the School Need (Success or Failure) condition. 
$p<.10)$. However, when the relationship is examined within conditions, the finding holds for Failing teams (rho $=-0.73, p<.05$ ) but not for Successful teams (rho $=0.12$, NS). So it appears that for Successful teams, which set moderate goal discrepancies, no relationship exists between size of goal discrepancy and subsequent group performance, but among Failing groups, where the range of discrepancy is larger, there is a significant negative relationship between group performance and the amount that group goals are set above prior performance levels.

\section{DISCUSSION}

The results demonstrate a gratifying similarity, at least on a phenotypic level, between group goal setting in laboratory groups and in United Fund executive boards. Since the hypotheses of the experimental study were suggested initially by data collected from United Funds, it is meaningful to consider the implications of the experimental results for decision-making in United Funds.

A major finding is that the three factors studied have independent and additive effects on increasing the size of the difference between past group performance levels and future group goals. The generalization of this finding to United Fund goal setting has several interesting implications. The main implication is that while external pressures may account for the general tendency to raise group goals to high levels, such pressures cannot explain the differences in goal-setting between Successful and Failing UF towns. In other words, external pressures have a constant rather than a differential effect on group aspirations among laboratory groups and perhaps also among UF towns. An additional implication is that perceiving oneself to be a member of a good board in a failing town or a member of a poor board in a successful town may be equivalent in terms of the tendency to raise goals to high levels. This assumes that the effects of each factor are approximately equal in addition to being independent, an assumption that can only be tested in the actual real-life situation.

While the major finding about group aspirations concerns the nature of the relationships among certain antecedent variables, the substantive interest of the study is to determine what particular processes, motivational and cognitive, may be involved in the choice of unattainable group goals. Each of the three predictions supported by the results is derived from a hypothesis about the processes involved.

The first hypothesis stated that the choice of an unattainable goal for the group is a function of the relative strengths of approach and avoidance achievement tendencies among members. Past studies have shown that repetitive failure experiences for groups may induce dis- 
positions among members to avoid the negative consequences of failure (cf. Zander \& Medow, 1965). When the group avoidance tendencies are stronger than tendencies to approach group success, members select goals which are less intermediate and less challenging than when the relative strength of these tendencies is reveresd (cf. Forward, 1969). In the present experiment, support for the first prediction about differences between Successful and Failing groups is in effect a replication of past findings and provides further support for the hypothesis that extreme group goal-setting is a function, at least in part, of group achievement tendencies aroused among members. Additional support for the first hypothesis is found in the responses to post-experimental questions which asked about felt responsibility for the group score and the degree to which the official group goal served as a personal criterion for group success or failure. Members of successful teams, like members of successful UF towns, rate these questions higher than do members of failing teams and towns.

The second hypothesis stated that excessively high goal setting in United Funds is a cognitive process of matching the dollar amount of a campaign goal to the dollar estimate of community need. Under this hypothesis the question of how much is needed overrides the question of how likely it is that the goal will be attained.

Two assumptions link this hypothesis to the second prediction. The first assumption is that members of High Need schools would in fact perceive that their school needed more points than members of Low Need schools. This assumption is supported by the data. A second more crucial assumption is that members utilize their perceptions of school need as a basis for setting team goals. This assumption is supported insofar as the High Need teams set much higher goals than Low Need teams.

An alternative explanation for the goal-discrepancy differences found between teams belonging to High or Low Need schools is that this condition may induce motivational tendencies similar to those engaged by the team Success and Failure conditions. But indirect evidence exists to counter this alternative interpretation. As mentioned earlier, the members of High Need ("failing") schools believed it was more important that their school beat other high schools, whereas typically members of successful teams rate it as more important to do better than other teams (Zander, 1968). Also, none of the differences which supported the motivational interpretation for Successful and Failing teams (felt responsibility, goal as criterion) were found for the School Need condition.

The third hypothesis states that the choice of unattainable group 
goals is a function of the strength of external group pressures acting upon the decision-makers to raise the level of the group goal. The results support the hypothesis; the stronger the pressures the greater the discrepancy between group performance and future goals. The finding that external pressures have effects which are independent of other factors in the experiment leads us to accept the explanation that differences between Success and Failure UF towns are due to differences in the strength of external pressures faced by board members in these towns. An alternative explanation, that board members in Success and Failing UF towns differ only in their susceptibility or conformity to these pressures receives no support from the experimental data.

The performance results of the experiment complement the performance analyses made for United Fund campaigns over several years. For Failing teams, but less so for Failing towns, a negative relationship exists between size of goal discrepancy and future performance. For Successful UF towns, a positive relationship is found between size of goal discrepancy and performance but this relationship is much weaker for Successful teams in the experiment. It may be noted that whereas the United Fund performance analysis was based on a total of 147 towns, the performance analysis for the experiment is based on a total of only 16 groups. However, the experimental results clearly demonstrate that the setting of unattainable goals not only ensures nominal failure (non-attainment of stated goal) but also has a detrimental effect on actual performance.

In conclusion, the present experiment supports three hypotheses about the processes involved in the setting of unattainable campaign goals by United Funds which fail year after year. Each of three different factors was found to have independent and additive effects upon increasing the level of a group goal above prior attainment levels. The first is a motivational factor; members of failing towns develop strong dispositions toward avoiding the negative consequences of group failure and so set extremely high goals which cannot be used and in fact are not used as criteria for good achievement. A second factor is cognitive; members of failing towns which face higher needs for welfare money than members of successful towns tend to match the dollar amount of the campaign goal with the dollar amount of community need without consideration as to whether such a goal is attainable or not. A third factor takes account of the environment of a UF board, particularly the pressures that are brought to bear by outside groups to raise the level of a campaign goal. These pressures are assumed to be stronger for failing than successful towns. One important 
consequence of excessively high goals, both for experimental teams and UF towns, is that they are associated with poor performance. Increasing the size of the discrepancy between past performance and future goals does not have a facilitating effect on subsequent performance as some may believe, but rather the reverse seems to be true.

\section{REFERENCES}

Forward, J. R. Group achievement motivation and individual motives to achieve success and to avoid failure. Journal of Personality, 1969, 37, 297-309.

ZaNDER, A., \& MEADOW, H. Strength of group and desire for attainable group aspirations. Journal of Personality, 1965, 33, 122-139.

ZANDER, A., MEDow, H., \& EFroN, R. Observers' expectations as determinants of group aspirations. Human Relations, 1965, 18, 273-287.

Zander, A., \& Newcomb, T., JR. Group levels of aspiration in United Fund Campaigns. Journal of Personality and Social Psychology, 1967, 6, 157-162.

Zander, A, \& Forward, J. Position in group, achievement motivation and group aspirations. Journal of Personality and Social Psychology, 1968, 8, 282-288.

ZANDER, A., Fonward, J., \& ALBERT, Rosita. Adaptation of board members to repeated failure or success by the organization. Organizational Behavior and Human Performance, 1969, 4, 56-76.

Received: February 9, 1970 